\title{
Modeling and Simulation to Improve the Efficiency of Transportation Systems: A Tool for Decision Support
}

Erma Suryania,* , Rully Agus Hendrawana, Philip Faster Eka Adiprajab, Rarasmaya Indraswaric, Ervina Ahyudanarid, Achmad Jauharie, Prasetyo Prambayantof

*Correspondence: erma.suryani@gmail.com.

aDepartment of Information Systems, Institut Teknologi Sepuluh Nopember, Surabaya, Indonesia bSTMIK Asia Malang, Indonesia

cDepartment of Informatics, Institut Teknologi Sepuluh Nopember, Surabaya, Indonesia

${ }_{d}$ Department of Civil Engineering, Institut Teknologi Sepuluh Nopember, Surabaya, Indonesia

eDepartment of Informatics, Universitas Trunojoyo Madura

fDepartment of Transportation Infrastructure, Transportation Department of Surabaya City

\section{Abstract}

This paper addresses problem solving and complex decision making in the management of transportation operations under environmental dynamics through the use of models and scenarios. A system dynamics simulation was used to model and analyze the efficiency of transportation systems as a tool for decision support to improve efficiency. Transportation systems are complex because they involve a number of different stakeholders, resulting in feedback with different time lags between the responses of all entities. Data and information were collected from the Transportation Department of Surabaya city. Several scenarios to improve the efficiency of transportation systems were developed by modifying the structure and parameters of the model. Several factors influence the efficiency of transportation system: traffic network, conventional roadway, accessibility based transport planning, multi modal transport, planning efficiency, and resources efficient modes (economic category). By implementing a number of strategies (such as the improvement of planning efficiency; multimodal transport development; route-based performance improvement), transportation system efficiency in Surabaya was predicted to be improved from $56 \%$ in 2019 to $66 \%$ in 2040 . The novel contributions of this research are: formulating relationships among several variables, modeling dynamic behavior of transportation system efficiency, and building scenario models to improve transportation operation efficiency. This research contributes to the literature by investigating these relationships through the use of models and experimental scenarios. 
Keywords: System dynamics; Decision making; Efficiency; Model; Simulation; Transportation systems; Scenario, Prediction

\section{Introduction}

Transportation systems are very complex and dynamic so it is difficult for transport planners to make decisions using traditional methods. Decision support system (DSS) technologies have been developed to improve the effectiveness of decision making in complex systems (1). DSS can assist transport planners in many areas. DSS can be used as a tool to evaluate strategies and policies that could enhance the efficiency of a transportation system. Transportation system efficiency refers to the ratio of inputs (costs) to outputs (benefits) (2). Economic efficiency can be measured using indicators such as cost/benefit ratio, net present value, and return on investment. Several factors influence the efficiency of transportation systems: 1) traffic network, 2) conventional roadway, 3) multimodal transport, 4) planning efficiency, 5) accessibility-based transport planning, and 6) economic efficiency.

- Traffic network: evaluates transportation system efficiency based on accessibility through better road network connectivity.

- Conventional roadway: evaluates roadway efficiency based on travel speed, which depends on roadway capacity and design speed.

- Multimodal transport: supporting and encouraging the use of resource-efficient modes.

- Planning efficiency: transportation systems are most efficient if planned, designed, and managed to support long-term strategic objectives and encourage more compact development.

- Accessibility-based transport planning: efficiency of a transportation system can be achieved through improving road network connectivity, supporting efficient modes, and encouraging more accessible land use.

- Economic efficiency: roads are most efficient when managed or priced to favor highervalue trips and more resource-efficient modes by facilitating more efficient transportation and public transport services. 
An efficient transportation system can reduce production costs and costs for consumers, thus enabling businesses to compete in the global market, increasing prosperity and economic growth (3). An efficient transportation system provides economic and social opportunities and benefits that can increase accessibility to markets, employment and additional investment (4), which can generate impacts that can be described as follows:

- Direct impacts: improved capacity and efficiency, which leads to more added value, larger markets and cost improvements.

- Indirect impacts: provision of indirect added value to employment through transportation links with other economic sectors

- Induced impacts: lower prices of commodities, goods and services, and increased operational efficiency of the transportation system.

Current transportation problems in Indonesia include the following (5):

1) Development limitations: the high economic growth in recent years has caused income inequality, development growth has been concentrated in the western regions while remote and border rural areas still lack connections with cities, markets, and services; urbanization imposes a heavy burden on basic service provision, increases congestion and declines city resources; widespread public transportation modes that are not used optimally; inadequate road transportation infrastructure; a crisis in urban mobility, with cars and motorcycles dominating urban centers, resulting in high levels of congestion and pollution; slow development and poor quality of the transportation infrastructure caused by the low level of investment in the sector, while the available funding cannot meet the increasing demand for urban transportation.

2) Legal and regulatory framework: the planning and implementation of transportation infrastructure in Indonesia is very bureaucratic and impractical. The entire transportation planning process is guided by the National Development Planning Agency (BAPPENAS) in coordination with the Ministry of Finance and the Ministry of Finance; 
the dominance of private vehicles, primarily cars and motorbikes, has led to an enormous energy demand for fuel, with an annual consumption growth rate of about 4.5\%; inadequate infrastructure, poor market access, and inefficient spatial structures impeding business growth and degrading the quality of living.

3) Land-use planning: development and investment plans lack direction, urgency, or strategic priorities.

4) Urban mobility: traffic congestion results in low mobility due to the lack of modal sharing (there are no urban rail systems); increasing urbanization and loss of public space cause high volumes of private vehicles, environmental degradation (high levels of air pollution), and loss of business productivity, negatively impacting investment and Gross Domestic Product (GDP).

In this research we utilized Surabaya city (East Java - Indonesia) as a case study based on the consideration that Surabaya faces several problems related to its transportation system, such as congestion caused by the increasing volume of vehicles, the continuing growth of the number of private vehicles, which dominate road use as well as the lack of convenient and fast public transportation. Based on the Castrol Magnatec Stop-Start Index (6), Surabaya is the fourth most congested city in the world.

Some approaches to solve these transportation problems are: the implementation of electronic road pricing (ERP), and mass rapid transit (MRT) and Bus Rapid Transit (BRT) development (7). Pfaffenbichler (2011) utilized system dynamics as a method to bridge the gap between politics, planning and science by developing land-use and transport models (8). Jiang and Seidmann (2014) analyzed capacity planning and performance contracting for service facilities. They found that the success of significant initial capacity investment is determined by the daily operations of several facilities (9). Qualitative and quantitative models can be used to develop the dynamic behavior of land-use. The transport interaction model MARS (Metropolitan Activity Relocation Simulator) allows to select policies and evaluate their impact on a transportation system using a flight simulator interface. Haghani, 
et al. (2003a) have developed a model for analyzing the causal relationships between various models, consisting of 7 sub-models: population, migration, household, employment, housing and commercial development, travel supply and demand effects (10). They found that vehicle miles traveled (VMT) is influenced by the total number of trips and the average trip distance. Haghani, et al. (2003b) have evaluated the impact of road capacity expansion and land-use change affecting the demand and performance of transportation networks using a system dynamics (SD) model that can predict the impacts of highway capacity expansion on land use and transportation system performance (11). Shen, et al. (2009) have developed a high-level model to compare low/high density land-use policies in Hong Kong (12). They found that a compact high-density scenario with investments in rail-based transportation is more sustainable compared to a car infrastructure, which is more prominent in the case of low density. Jifeng, et al. (2008) have developed a high-level model of the interactions between population, vehicle ownership, environment, GDP, travel demand, and infrastructure supply (13). They recommended that the port city of Dalian in China should restrict the total number of vehicles to improve the sustainability of its transportation system.

All the above studies deal with urban transport, demand/highway capacity management, infrastructure supply, and transportation system performance. Based on previous studies, this research makes a novel contribution by analyzing transportation system efficiency based on existing conditions and by developing a number of scenarios to improve efficiency, considering a number of factors, i.e. traffic network, conventional roadway, accessibility-based transport planning, multimodal transport, planning efficiency, and economic efficiency. The novel contributions of this research are formulating relationships among variables, modeling the dynamic behavior of transportation system efficiency, and building scenario models to improve the efficiency of transportation systems. References related to the efficiency of transportation systems were used as basic knowledge in developing the SD model. Validation was carried out to check the model's validity using historical data collected from the Transportation Department of Surabaya city. With the 
validated model, several potential strategies for improving the efficiency of Surabaya's transportation systems were tested and evaluated through structural scenarios. The scenarios were developed based on a number of proposed strategies for intelligent transport solutions (14), i.e. a passenger monitoring system to reduce bus start/stops and create faster public transport; improvement of planning efficiency through demand and capacity planning (2); multimodal transport development through MRT and BRT development; route-based performance improvement through travel time delay reduction; and the elimination of daily charges for public transport. The questions that guided this research were:

1. What factors influence transportation system efficiency?

2. How can the efficiency of transportation systems be improved through the use of models and scenarios?

3. How can dynamics models and scenarios to support decision making in improving the efficiency of a transportation system be implemented?

To answer the research questions and accomplish the research objectives, an SD model was utilized because it provides a useful tool to support policy analysis and decision making. A set of models of the efficiency of transportation systems was developed based on the existing conditions to learn about the behavior of the system. We also developed a number of scenarios (i.e. intelligent transport solutions; improvement of planning efficiency through demand and capacity planning; multimodal transport development; and routebased performance improvement) to improve the efficiency of the transportation system.

This paper is organized as follows. Section 2 describes the efficiency of transportation systems. Section 3 explains system dynamics as a tool for model development. Section 4 explains the development of the model. Section 5 discusses the results. Section 6 demonstrates the scenario development. Finally, Section 7 provides our conclusions and suggestions for further research. 


\section{Decision support in improving the efficiency of transportation systems}

The use of decision support systems can help professionals in transportation planning, urban planning, public policy planning, public transport operations, service industries and logistics as well as individual users in planning travel and managing transportation systems (15). Monitoring traffic conditions, listing all possible travel alternatives, and calculating fares is a useful part of transportation management in terms of: 1) increasing the productivity of a transportation system; 2) improving safety; 3) improving efficiency; 4) increasing mobility and accessibility; 5) improving intermodal connections. Engebrethsen and Dauzère-Pérès (2019) conducted a literature review for transportation mode selection in inventory models (16). They found that the significance of transportation costs and mode selection in inventory models has increased due to cost optimization for the whole supply chain. They proposed several directions for future research: 1) the development of methods to improve computational efficiency through the use of models that consider different discounts and capacities, and 2) the development of models and approaches that support multimodal replenishment decisions for dynamic deterministic demand and multiple items with several less than truck load (LTL) price-break intervals and different capacities.

An efficient and sustainable transportation system requires the integration of transportation coordination, land-use planning, and building mobility options (17). There are several ways to define the efficiency of a transportation system. Conventional planning evaluates the performance of transportation systems based on mobility and travel time. The new planning paradigm evaluates the performance of transportation systems based on accessibility, which reflects the ability to access services and activities (2). Quantitatively, efficiency refers to the ratio between input (costs) and output (benefits), which can be measured from the ratio between benefits and costs. Meanwhile, from a qualitative point of view, efficiency can be measured from economic development, safety, and pollution reduction. Factors that can be used to measure the efficiency of a transportation system are traffic network, roadway capacity and design speeds, multimodal transport, planning 
efficiency, accessibility-based transport planning, and economic efficiency (2), as described in the introduction section.

An efficient transportation system will be achieved when the transportation destination can be reached with reduced vehicle miles traveled (VMT) (18). Reducing VMT can reduce overall transportation costs. The VMT reduction strategy can be carried out through transportation demand management. This will reduce traffic congestion, enable more efficient use of vehicles, reduce emissions, reduce vehicle wear, and save travel time. Decision makers can improve efficiency by implementing the following strategies (14) (18):

a. Mass transit: encouraging and enabling the community to increase mobility by using mass transit.

b. Multimodal transportation: providing multiple modes of transportation to increase mobility and reduce VMT.

c. Intelligent transportation: providing a system that can monitors passengers getting on/off the bus so when a bus is full an extra bus can be deployed on the same route. This system can reduce fuel consumption (due to reduced bus start/stops) while creating faster public transport.

\section{System dynamics as a tool of modeling complex systems for decision support}

System dynamics (SD) is a modeling method that is useful in managing business performance over time (19). SD is a methodology developed by Forrester from MIT in the 1950s-60s based on system theory, information science, organizational theory, and control theory. SD modeling has demonstrated considerable value across different fields to help decision makers to learn and predict the dynamic behavior of complex systems for the development of effective policy actions. Complex systems are usually defined as a phenomenon consisting of a large number of elements organized in a multi-level hierarchical structure. SD modeling helps managers to improve a company's performance according to their vision. SD focuses on feedback and causal relationships between model 
variables that interact in the system and determine its performance. Scenario-based planning using SD can demonstrate cause-and-effect relationships in dynamic characteristics, so companies can respond appropriately to reduce their impact on performance. System dynamics (SD) is an approach to develop computer models with large scale parameters $(20)$.

SD has been applied in several fields, such as government policy, medicine, the automotive industry, and urban studies (21). In this research, SD was utilized to develop a set of models for improving the efficiency of transportation systems based on the following considerations:

a. SD is a holistic approach that is suitable for application in solving urban transport problems.

b. SD provides modeling structures and explores factors that drive the efficiency of a transportation system.

c. SD can be built using input from stakeholders for policy design and implementation.

Suryani, et al. (2012) have developed a model to investigate air cargo demand (22). They found that SD is a useful tool for demand capacity planning as it includes the underlying structure of the problem and has the possibility to reveal the implications of several factors. Brailsford, et al. (2019) have utilized hybrid simulation modeling (discrete event simulation (DES), system dynamics, and agent-based simulation) in operational research to provide a new framework based on a simulation life cycle that can be useful for future modelers (23). They found that SD has two critical aspects that are important to consider: 1) it explicitly provides the concept of feedback, which is useful when moving away from short-term dynamics to long-term planning; 2) SD provides the concept of stock and flow, which are aligned with queues and activities in DES and also offers the possibility of storing information. SD has some advantages over traditional transport modeling due to its capability to underlay the problem structure and understand the implications of optimistic scenarios and the factors that influence the need for additional capacity of airport 
infrastructure (22). Compared to other methods, such as discrete event simulation (DES), SD can accommodate qualitative matters and can map system variables in causal relationships (24), while DES has traditionally been used at the operational or tactical level. SD is well suited to strategic issues because it can be used as a tool for policy analysis and decision making (25). Ventana Simulation (Vensim) is a modeling language that can provide support for SD model development; it is more flexible than other software and enables to integrate stock and flow and causal loop components (26).

\section{Model development}

Developing a system dynamics model consists of several steps (21): 1) problem definition and articulation: in this step we define the problems, determine the model's purpose, identify the model's components, time horizons, and data requirements; 2) dynamic hypotheses: in this step, we formulate the dynamic hypotheses, generating initial hypotheses in terms of a causal loop diagram (CLD) and converting the CLD into a stock and flow diagram (SFD); 3) simulation model development: in this step, we define the model formulation, set the initial conditions and check the model's consistency using the model outputs; 4) model validation: this step is required to check the model's accuracy; 5) scenario (experimentation) development: applying a 'what if?' analysis of the model based on the proposed strategy by modifying the model's structure. This section describes the definition and articulation as well as the dynamic hypotheses, which includes CLD development, SFD construction, and model formulation.

\section{Problem definition and articulation}

In this step, we define the problems, determine the model's purpose (objective), and identify the model's components, time horizons, and data requirements with reference to several problems in the transportation systems, such as: development limitations; the dominance of private vehicles; land-use planning that lacks direction, urgency or strategic priorities; traffic congestion that results in low mobility. In this study, the research objective was to improve transportation system efficiency by considering a number of factors (traffic 
network, conventional roadway, multimodal transport, planning efficiency, accessibilitybased transport planning, and economic efficiency).

The model components can be obtained by determining the model boundaries in order to generate the behavior of interest (27). To determine the model boundaries, the following previous researches related to the efficiency of transportation systems were explored:

a. Litman (2013): the efficiency of a transportation system can be measured from several factors, such as traffic network, roadway capacity and design speeds, multimodal transport, planning efficiency, accessibility-based transport planning, and economic efficiency (2).

b. United Nations (2012): connectivity can be improved by the use of intelligent transport solutions (ITS) through a passenger monitoring system in order to support the traffic network (14).

c. Government of Singapore (2018): accessibility of public transport services is an important factor in public transport service and influences the efficiency of a transportation system (28)

d. Hyde \& Smith (2017): connectivity depends on network components such as streets, railways, walking and cycling routes, services and infrastructure interconnections (29).

e. Government of Singapore (2018): network connectivity depends on the role of feeder services as well as the design of terminals and stations (28).

f. Moses, et al. (2013): highway performance evaluation can be measured from traffic speed, road volume, road capacity, and travel time delay (30).

g. Li, et al. (2013): travel cost is one of the most important factors that influence public transport operation and has an impact on transport performance (31).

To select the model components, the following guidelines were considered (27):

1) They should represent the system's behavior related to the model's purpose.

2) They should be aggregated to avoid unnecessary complications but still represent the system being modeled. 
3) They should have a directional name and have to be able to increase or decrease.

4) They should be divided into two categories: endogenous (internal) and exogenous (external) components.

Based on the above researches, we defined a number of model components, consisting of endogenous (internal) and exogenous (external) components, as shown in Table 1. In this research, we set the model simulation for 18 years (2000-2018) based on the consideration that within that time frame, the system's behavior could be learned. Regarding the research objectives, some data were required, i.e.: city population, public transport rates, public transport supply, average travel time, and travel time delay in the transportation systems.

Table 1. Model Components for the Efficiency of Transportation Systems

\begin{tabular}{ll}
\hline Endogenous Components & Exogenous Components \\
\hline Planning Efficiency & Transport Demand \\
Economic Efficiency & Population \\
Accessibility & \\
Traffic Network & \\
Conventional Roadway & \\
Transport Supply & \\
Multimodal Transport & \\
Vehicle Miles Traveled & \\
Travel Time Delay & \\
Road Volume \\
Road Capacity \\
Land-use Development
\end{tabular}




\section{Dynamic hypotheses}

In this step, the formulation of the dynamic hypotheses through the development of a causal loop diagram (CLD) and a stock and flow diagram (SFD) is conducted.

\section{CLD development}

A causal loop diagram is a qualitative method to visualize how variables in a system are interrelated and influence each other. It explains the system's behavior by demonstrating a collection of connected nodes and feedback loops, such as reinforcing and balancing loops. A reinforcing loop $(\mathrm{R})$ represents a change in a node in the same direction, which causes the loop to grow or decline. Meanwhile, a balancing loop (B) represents a change in the opposite direction, which causes the loop to balance its behavior. In this research, the development of the causal loop diagram was performed by referring to previous researches related to the efficiency of transportation systems as described in the problem formulation. The CLD of transportation system efficiency can be seen in Fig. 1.

Fig. 1. Causal loop diagram of transportation system efficiency.

As can be seen from Fig. 1, there are two balancing loops (B1, B2) and five reinforcing loops (R1, R2, R3, R4, R5) in the CLD. Transportation system efficiency is influenced by traffic network, conventional roadway, multimodal transport, planning efficiency, accessibility-based transport planning, and economic efficiency. An increase in transportation system efficiency results in a decrease in transport demand; an increase in transport demand encourages the addition of transport supply; an increase in transport supply with resource-efficient modes results in an increase in transportation system efficiency (B1). An increase in transport supply results in an increase in transport availability and multimodal transport, hence increasing the efficiency of the transportation systems; an increase in efficiency of the transportation systems results in a decrease in transport demand; an increase of transport demand encourages the addition of transport supply (B2). 
An increase in conventional roadway results in an increase in route-based performance evaluation (R1). An increase in economic efficiency results in an increase in resourceefficient modes (R2). An increase in transport availability results in a decrease in multimodal transport and transportation system efficiency; an increase in transportation system efficiency results in an increase in network connectivity; an increase in network connectivity encourages railway system development and transport availability (R3). An increase in network connectivity encourages railway system development (R4). An increase in system accessibility results in an increase in accessibility-based planning, transportation system efficiency, and economic efficiency (R5).

\section{SFD development and model formulation}

A stock and flow diagram is a calculable representation of the system being modeled. It consists of specific symbols and components representing the structure of the system. Stocks are things that can accumulate, while flows represent rates of change. Based on a CLD of transportation system efficiency, a stock and flow diagram (SFD) can be developed to characterize the accumulation of stock and flow quantities in the transportation system. Several steps are required to convert a CLD to an SFD: 1) identifying the main factors giving rise to problems that affect transportation system efficiency; 2) defining stock, flow, and auxiliary variables associated with the main factors; 3 ) providing the rate of change that governs each stock; 4) analyzing the relationships between the variables as well as the impacts of changes on the other variables. The SFD of transportation system efficiency can be seen in Fig. 2.

Fig. 2. SFD of transportation system efficiency.

Transportation system efficiency is influenced by several factors: traffic network, conventional roadway, accessibility-based transport planning, multimodal transport, planning efficiency, and economic efficiency. The model formulation of public transportation efficiency can be seen in Eq. (1). 
$\operatorname{TSE}(\mathrm{t}+1)=\operatorname{TSE}\left(t_{0}\right)+\int \frac{A B T P(t)+C R(t)+E E(t)+M M T(t)+P E(t)+T N(t)}{6} * \frac{1}{100} * \frac{\operatorname{TSE}(\mathrm{t})}{100}$

where:

TSE $\quad=$ Transportation System Efficiency

ABTP $=$ Accessibility-Based Transport Planning

$\mathrm{CR}=$ Conventional Roadway

$\mathrm{EE} \quad=$ Economic Efficiency

MMT = Multimodal Transport

$\mathrm{PE} \quad=$ Planning Efficiency

$\mathrm{TN} \quad=$ Traffic Network

Traffic network evaluates transportation system efficiency based on automobile access. It depends on traffic speeds performance, infrastructure, and network connectivity. More road network connectivity will increase traffic speed. The SFD of network connectivity can be seen in Fig. 3.

Fig. 3. SFD of network connectivity

As can be seen from Fig. 3, network connectivity depends on services and infrastructure interconnectivity, role of feeder services, walking and cycling routes, railways, terminals and stations, and route-based performance evaluation. Network connectivity is the level of interconnection between network components such as roads, railways, walking and cycling routes, services and infrastructure (29). Terminals and stations are facilities where passengers are assembled or dispersed. They may be points of interchange within the same modal system that ensure the continuity of the flows. They are also important factors of transfer between modes, increasing network connectivity. The role of feeder services is to connect public transport users between origin and destination to the main public transport routes in the network. Additional investment in feeder services will increase the connectivity of the public transport and pedestrian networks, hence leading to greater 
network connectivity (32). The model formulation of network connectivity can be seen in Eq. (2).

$\mathrm{NC}(\mathrm{t}+1)=N C\left(t_{0}\right)+\int \frac{R(t)+R F S(t)+R B P E(t)+S I I(t)+T S(t)+W C R(t)}{6} * \frac{1}{100} * \frac{\mathrm{NC}(\mathrm{t})}{100}$

where :

$\mathrm{NC} \quad=$ Network Connectivity

$\mathrm{R} \quad=$ Railways

RFS $=$ Role of Feeder Services

RBPE = Route-based Performance Evaluation

SII $\quad=$ Services and Infrastructure Interconnect

TS $=$ Terminals and Stations

WCR = Walking and Cycling Routes

Route-based performance evaluation can be measured from traffic speed, road volume, road capacity, and travel time delay (30). Travel cost of public transport is one of the most important factors that influence public transport operation and has an impact on performance evaluation in terms of economic factors (31). Besides the travel cost, the annual net income of public transport and the capital cost of public transport are the other important economic factors that influence route-based performance. The SFD of routebased performance evaluation can be seen in Fig. 4. The model formulation for route-based performance evaluation can be seen in Eq. (3) and Eq. (4).

Fig. 4. Route-based performance evaluation.

$\operatorname{RBPE}(\mathrm{t})=\frac{S P(t)+E C(t)+D I(t)+\frac{R V(t)}{R C(t)}}{4} * \frac{R P E F}{100}$

where:

RBPE = Route-based Performance Evaluation

$\mathrm{SP} \quad=$ Speed Performance 
DI = Delay Impact

$\mathrm{RV} \quad=$ Road Volume

RC = Road Capacity

RPEF $=$ Road Performance Evaluation Factors

$\mathrm{EC}=\frac{1}{2} *\left(\left(\frac{\operatorname{PTANI}(t)}{\operatorname{PTCC}(t)} * 100\right)+\operatorname{PTCI}(t)\right)$

where:

$\mathrm{EC}=$ Economic Category

PTANI = Public Transport Annual Net Income

PTCC = Public Transport Capital Cost

PTCI = Public Transport Cost Index

Conventional roadway represents conventional indicators that can be used to measure the efficiency of a transportation systems, such as traffic speed, road volume, road capacity, travel time delay, affordability (economic indicator) as factors that influence a transportation system's performance (33) and affect its efficiency. Accessibility represents the ease of reaching or interacting with destinations. Land-use development and system accessibility are two factors that have an impact on accessibility-based transport planning (34). Density, land-use mix, roadway connectivity, non-motorized (walking and cycling) conditions are factors that influence land-use development (35). Density represents the number of people or jobs in a certain area. Land-use mix is the allocation of various types of land-use (residential, commercial, institutional, recreational, etc.) close together. Connectivity represents the connection between roads or lanes and travel destinations. Non-motorized conditions are conditions that reflect the quantity and quality of sidewalks, crossings and pathways, the connectivity of the bicycle track system, safety and attractiveness of pedestrian facilities, and supporting features such as bicycle racks.

System accessibility is determined by the following factors: demographic and socioeconomic characteristics, number and diversity of destinations, user location, travel 
efficiency, and travel mode choices (36). Multimodal transport represents the availability of all types of transportation. Transportation systems are most efficient when they can support and encourage the use of resource-efficient modes, hence users can choose the most efficient option for each trip. Planning efficiency can be achieved when the transportation systems are planned, designed, and managed to support long-term objectives. Supply (capacity) and demand management of transportation systems is required to support managerial planning and control. The SFD of public transport supply and demand can be seen in Fig. 5. As can be seen from Fig. 5, public transport demand is influenced by the size of the city population. The ratio between public transport demand and supply is a comparison between public transport supply and demand. The model formulation of the ratio between public transport supply and demand can be seen in Eqs. (5)-(7).

Fig. 5. SFD of public transportation and demand.

$\operatorname{RPTSD}(\mathrm{t})=\frac{P T S(t)}{P T D(t)}$

$\operatorname{PTD}(\mathrm{t})=\operatorname{POP}(\mathrm{t}) * \frac{T D P(t)}{100}$

$\mathrm{POP}(\mathrm{t}+1)=\mathrm{POP}\left(t_{0}\right)+\int P G(t)$

where:

RPTSD $=$ The Ratio of Public Transport Supply and Demand

PTS = Public Transport Supply

PTD = Public Transport Demand

POP = Population

TDP $=$ Transportation Demand Percentage

PG = Population Growth 
Economic efficiency represents consumer benefits of utilizing facilities such as roads (2). From this point of view, a transportation system is most efficient when managed to provide more resource-efficient modes.

\section{Model validation}

Checking the model's validity was done using historical data during the time horizon of the simulation (2000-2018). We considered this time frame based on data availability and system behavior. Information on road volume and fair rate of public transport were collected from the Department of Surabaya City Transportation. Traffic counting was carried out for 16 hours from 05.00 to 21.00 with 10 -minute intervals. Meanwhile, historical city population data were obtained from Badan Pusat Statistik Kota Surabaya. The model was deemed valid if the error rate was $\leq 5 \%$ and the error variance was $\leq 30 \%$ (37). The error rate is a comparison of the difference between the average of the simulation model and the average of the historical data, and the average of the historical data. Error variance is a comparison of the difference between the standard deviation of the simulation model and the standard deviation of historical data, and the standard deviation of the historical data. The model was validated by checking the error rate and error variance as shown in Eqs. (8)-(9).

Error Rate $=\frac{[\overline{\mathbf{S}}-\overline{\mathbf{A}}]}{\overline{\mathbf{A}}}$

Error Variance $=\frac{[\mathrm{Ss}-\mathrm{Sa}]}{\mathrm{Sa}}$

where:

$\bar{S}=$ average rate of simulation

$\bar{A}=$ average rate of data

$\mathrm{A}=$ data at time $\mathrm{t}$

$\mathrm{S}=$ simulation result at time $\mathrm{t}$

$S_{S}=$ standard deviation of simulation 
$S_{a}=$ standard deviation of data

The software used for the model development was Ventana Simulation (Vensim) based on the following considerations (26): 1) Vensim allows modelers to easily mix SFD and CLD with its functionality; 2) Vensim contains a set of analysis tools that use the structure of the model to present information quickly in investigating sources of behavior. The error rates of population, route volume, and fare rates were:

Error rate 'population' $=\frac{[2,761,733-2,764,268]}{2,764,268}=0.0009$

Error rate of 'route volume' $=\frac{[1.394 .044-1,406,148]}{1,406,148}=0.0086$

Error rate of 'fare rates of transportation system' $=\frac{[3,684-3,625]}{3,625}=0.0162$

The error variances of population, route volume, and fair rates were:

Error variance 'population' $=\frac{[91,231-91,604]}{91,604}=0.0041$

Error variance of 'route volume' $=\frac{[360,675-363,338]}{363,338}=0.0073$

Error variance of 'fare rates of transportation system' $=\frac{[830-972]}{972}=0.1460$

A comparison between the simulation results and the historical data of population, route volume, and fare rates can be seen in Figs. 6-8.

Fig. 6. Comparison of simulation result and historical data of the population.

Fig. 7. Comparison of simulation result and historical data of the route volume.

Fig. 8. Comparison of simulation result and historical data of the fare rates. 


\section{Results and discussion}

This section discusses the simulation results of the transportation system's efficiency, traffic network, conventional roadway, accessibility-based transport planning, and planning efficiency based on the existing conditions from 2000 to 2018. Traffic network, conventional roadway, and planning efficiency are important factors that influence transportation system efficiency. From the SFD of transportation system efficiency and its drivers (traffic network, conventional roadway, accessibility-based transport planning, and planning efficiency), we obtained the simulation results within the period of simulation.

Fig. 9 represents the simulation result of transportation system efficiency in Surabaya (Indonesia). The simulation result shows that transportation system efficiency in Surabaya (Indonesia) is low (50-56\%) due to several factors, i.e. traffic network, conventional roadway, and planning efficiency, as can be seen in Fig. 9.

Fig. 9. Transportation system efficiency based on the existing conditions.

The traffic network fluctuated with a minimum value of $46 \%$ and a maximum of 57 due to network connectivity and traffic speed performance, as shown in Fig. 10. The percentage of network connectivity was low, below $53 \%$. This percentage increased annually with an average growth rate of $0.58 \%$ per year due to services and infrastructure interconnectivity, role of feeder services, walking and cycling routes, railways, terminals and stations, and route-based performance evaluation. Better road network connectivity increases traffic speed performance.

Fig. 10. Traffic network based on the existing conditions.

Conventional roadway assesses transportation system efficiency based on travel speed. Hence, increased road capacity and design speed are required to improve efficiency. The simulation result shows that conventional roadway fluctuates with a minimum of $19 \%$ and a maximum of $42 \%$ due to route-based performance, as can be seen in Fig. 11.

Fig. 11. Conventional roadway. 
Route-based performance is influenced by traffic speed, road volume, road capacity, and travel time delay. The simulation result shows that route-based performance was low, below $20 \%$. This was due to traffic speed, the ratio between road volume and capacity, and travel time delay. The ratio between road volume and capacity fluctuated with a minimum of $54 \%$ and a maximum of $104 \%$, which means that the vehicle volume (daily traffic) exceeded the road capacity. Travel time delay represents the time difference between actual travel time and free-flow travel time, which had a minimum of 15 minutes and a maximum of 30 minutes.

Accessibility-based transport planning is influenced by system accessibility and landuse development. The simulation result shows that accessibility-based transport planning was low, below $37 \%$, due to system accessibility and land-use development, as can be seen in Fig. 12. System accessibility depends on the average travel distance and affordability of public transport.

Fig. 12. Accessibility-based transport planning.

Planning efficiency evaluates the efficiency of a transportation system based on the effectiveness and efficiency of planning, design, and management to support the strategic objectives. For example, infrastructure development to support the development of local commercial districts. The simulation result shows that planning efficiency tended to decline from $59 \%$ to $58 \%$ due to planning management, as can be seen in Fig. 13. Planning management in Surabaya faces several problems, such as congestion caused by the increasing vehicle volume, the growth of the number of private vehicles that dominate the use of roads, and the lack of convenient and fast public transportation.

Fig. 13. Planning efficiency-based on the existing conditions.

\section{Scenario development}

This section presents several scenarios that can be carried out to improve transportation system efficiency. Scenario development is a method of strategic planning that can analyze 
projections of key factors for the interpretation of future conditions (38), which is useful in decision making for complex systems. Scenarios can be developed to forecast and evaluate policy scenarios to learn about nonlinear dynamics (39). Scenario development can be done by modifying the model's structure and parameters (40). The following strategies can be implemented: implementing intelligent transport solutions such as a passenger monitoring system, electronic ticketing, and transport machine-to-machine communication (14); increasing public transport supply; the Bus Rapid Transit (BRT) and Mass Rapid Transit (MRT) development; and increasing route-based performance through the reduction of travel time delay (reducing delay) and improving economic factors. This research showed the impact of various policies on transportation management that can potentially be implemented to increase transportation system efficiency.

The proposed innovative transportation solution is a monitoring system that can monitor bus routes, time spent at bus stops, travel speed, distance traveled, and time of arrival and departure (14). This system enables to record passengers getting on and off the bus and when a bus is full, the system can send an extra bus to service the same route. This process can reduce fuel consumption, due to reduced bus start/stops, providing faster public transport for the passengers. Other innovative transport solutions are electronic ticketing, which can help passenger to plan their route and purchase tickets, and transport machineto-machine communication, which can monitor bus routes, time spent at bus stops, travel speed, distance traveled, and times of arrival and departure. All these strategies will influence network connectivity and infrastructure, which can improve the traffic network.

Conventional roadway can be improved through the improvement of route-based performance. Route-based performance can be measured from travel speed, road volume, road capacity, travel time delay, and economic factors. Improvement of route-based performance is required to improve the efficiency of the transportation system, which includes reducing travel time delay and improving economic factors through abolishing daily deposits for public transport drivers. System accessibility represents the ease of 
reaching destinations. This can be improved through the reduction of travel distance and improving the affordability of public transport.

Implementing multimodal transport through Bus Rapid Transit (BRT) and Mass Rapid Transit (MRT) development is required to improve the efficiency of the transportation system. MRT is a modern urban public transportation system that can carry large numbers of people. Challenges in MRT development include land acquisition for the relocation of public utilities, such as the removal of gas pipes, electricity cables, etc. The maximum capacity of MRT can be defined as 100 passengers per vehicle * 10 vehicles per train * 30 vehicle sets per hour $=30,000$ passengers per hour (41). BRT is a high-quality bus transit system that is fast, convenient, and cost-effective (42). To develop BRT projects in Indonesia, a large amount of funding is required; a 5-km BRT development would cost US\$ 5 million (43). The maximum capacity of one bus is 30 people per vehicle.

Increasing public transport supply is another strategy to improve the transportation system's efficiency. This can be done through the expansion of the public transport fleet. Currently, the public transport fleet in Surabaya consists of buses, taxis and lyns (a lyn is a type of public transportation with a carrying capacity of 10 passengers). This strategy is a solution to improve planning efficiency through supply (capacity) and demand management. The SFD of the improvement of the efficiency of transportation system is shown in Fig. 14. As can be seen from Fig. 14, the improvement of transportation system efficiency can be done through the improvement of traffic network, conventional roadway, accessibility-based transport planning, multimodal transport, and planning efficiency. The scenarios are highlighted with a green color to demonstrate some of the modified structures in the SFD of scenario planning.

Fig. 14. SFD of the improvement of the efficiency of the transportation systems.

The simulation result shows that by conducting the above strategies, transportation system efficiency is projected to improve from $56 \%$ in 2019 to $66 \%$ in 2040, as can be seen in Fig. 15. The efficiency of the transportation systems will increase on average by $0.75 \%$ 
per year. This is due to the improvement of network connectivity, route-based performance, system accessibility, and the improvement of the ratio between public transport supply and demand, as can be seen in Figs. 16-19.

Fig. 15. Transportation system efficiency after improvement (scenario).

Fig. 16. The improvement in network connectivity.

Fig. 17. The improvement in route-based performance.

Fig. 18. The improvement in system accessibility.

Fig. 19. The improvement in the ratio between public transport supply and demand.

As can be seen from Fig. 16, network connectivity increases slowly with an average growth of $0.7 \%$ per year due to the improvement of route-based performance and services and infrastructure interconnectivity. Route-based performance increases by $2.7 \%$ per year, hence it is predicted to reach $34 \%$ in 2040, as can be seen in Fig. 17. This is due to the reduction of travel time delay and improvement of economic factors.

System accessibility increases by $0.64 \%$ per year and is projected to reach $41 \%$ in 2040 , as can be seen in Fig. 18. This is due to the reduction of travel distance and the improvement of affordability. Increasing public transport supply will increase the ratio between public transport supply and demand, hence it will reach $33 \%$ in 2020, however, this value will decrease with increasing demand, as can be seen in Fig. 19.

\section{Conclusion and further research}

This research was designed to provide a comprehensive and objective assessment of improving transportation system efficiency through the use of simulation models and scenarios. To build the simulation models and develop the scenarios, we utilized system dynamics based on the consideration that systems dynamics can be developed at 
macroscopic and microscopic levels of transportation system efficiency to explore traffic network planning, conventional roadway, multimodal transport, planning efficiency, accessibility-based transport planning, and resource-efficient modes in terms of economic factors. This research was conducted in Surabaya, East Java, Indonesia, which is the fourth most congested city in the world. The novel contributions of this research are: formulating relationships between variables, building the dynamic behavior of transportation system efficiency as well as developing scenarios to improve transportation system efficiency. This paper contributes to the literature by theoretically and empirically investigating these relationships through the use of models and experimental scenarios such as implementing innovative intelligent transport solutions (passenger monitoring system, electronic ticketing, and transport machine-to-machine communication; increasing public transport supply; Bus Rapid Transit (BRT) and Mass Rapid Transit (MRT) development; and increasing route-based performance through the reduction of travel time delay and the improvement of economic factors), thereby addressing research gaps found in the literature. The scenarios enabled to test some alternative policies and observe the overall impact of the proposed solutions by modifying the model's structure and parameters.

Several factors influence transportation system efficiency, i.e. traffic network, conventional roadway, accessibility based transport planning, multimodal transport, planning efficiency, and resources efficient modes (economic category). Traffic network evaluates transportation system efficiency based on automobile access, hence it depends on traffic speed performance, infrastructure, and network connectivity. Conventional roadway depends on conventional indicators that can be used to measure the efficiency of the transportation system: traffic speed, road volume, road capacity, delay, affordability (economic indicator). All these indicators influence route-based performance.

Accessibility demonstrates the ease of reaching destinations. Land-use development and system accessibility are two factors that have an impact on accessibility-based transport planning. Density, land-use mix, roadway connectivity, non-motorized (walking and cycling) conditions are important factors that influence land-use development. System 
accessibility is influenced by average travel distance and affordability of public transport. Multimodal transport represents the availability of all types of transportation. Transportation systems are most efficient when they support and encourage the use of resource-efficient modes so users can choose the most efficient option for each trip. Planning efficiency can be achieved if the transportation systems are planned, designed, and managed to support long-term objectives. Supply (capacity) and demand management of the transportation system is required to support managerial planning and control. Economic efficiency represents consumer benefits of utilizing transport facilities; a transportation system is more efficient when it is managed to provide more resourceefficient modes.

The implementation of several strategies to support decision-making in improving the efficiency of transportation operations leads to positive results by implementing intelligent transport solutions such as a passenger monitoring system, electronic ticketing, and transport machine-to-machine communication; increasing public transport supply; Bus Rapid Transit (BRT) and Mass Rapid Transit (MRT) development; and increasing routebased performance through the reduction of travel time delay and the improvement of economic factors. Further research is required to develop a sustainable transportation system by considering economic (energy and pricing), social (improving safety and mobility), and environmental factors (reducing carbon emissions and improving land-use development).

\section{Availability of data and materials}

The dataset used and/or analyzed during the current research are available from the corresponding author on reasonable request.

\section{Competing interests}

The authors declare that they have no competing interests.

\section{Funding}

This research was partially funded by the Indonesian Ministry of Research, Technology 
and Higher Education under the Word Class University (WCU) Program, managed by Institut Teknologi Bandung.

\section{Author's contributions}

ES, RAH, PFEA developed the methodology and performed the experiments. The article is mainly written by ES. RI, EA, and AJ help provide the writing, discussions, and comments that were essential for the quality of the work. PP provides the data and information that was used in this research. All authors read and approved the final manuscript.

\section{Acknowledgments}

The authors thank the Indonesian Ministry of Research, Technology and Higher Education for its financial support under the Word Class University (WCU) Program that was managed by Institut Teknologi Bandung.

\section{References}

1. Bielli M. A DSS approach to urban traffic management. European Journal of Operational Research. 1992; 61(1-2): p. 106-113.

2. Litman T. Measuring transport system efficiency. Victoria. [Online].; 2013 [cited 2020 January 30. Available from: https://www.planetizen.com/node/59995.

3. Shuster B. Efficient transportation system is crucial to economy, way of life. [Online].; 2013 [cited 2020 January 20. Available from: https://thehill.com/specialreports/transportation-and-infrastructure-march-2013/287781-efficienttransportation-system-is-crucial-to-economy-way-of-life.

4. Rodrigue J, Notteboom T. Transportation and economic development. The geography of transport systems. 2012.

5. Leung KH. Indonesia's summary transport assessment Manila, Philippines: Asian Development Bank; 2016. 
6. Thrillis. The worst traffic in the world is in.... [Online].; 2015 [cited 2020 January 20. Available from: https://www.thrillist.com/travel/nation/city-with-worst-trafficjakarta-indonesia-tops-castrol-s-ranking-of-cities-with-most-stop-starts.

7. Raharjo HA. The alternative solution for traffic problem in Jakarta - Indonesia. International Journal of Business and Management Studies. 2012; 1(2): p. 315-320.

8. Pfaffenbichler P. Modelling with systems dynamics as a method to bridge the gap between politics, planning and science? Lessons learnt from the development of the land use and transport model MARS. Transport Reviews. 2011; 31(2): p. 267-289.

9. Jiang Y, Seidmann A. Capacity planning and performance contracting for service facilities. Decision Support Systems. 2014; 58: p. 31-42.

10. Haghani A, Lee S, Byun J. A system dynamics approach to land use/transportation system performance modeling part I: Methodology. Journal of advanced transportation. 2003a; 37(1): p. 1-41.

11. Haghani A, Lee S, Byun J. A system dynamics approach to land use / transportation system performance modeling. Part 2: Application. Journal of Advanced Transportation. 2003b; 37(1): p. 43-82.

12. Shen Q, Chen Q, Tang B, Yeung S, Hu Y, Cheung G. A system dynamics model for the sustainable land use planning and development. Habitat International. 2009; 33(1): p. 15-25.

13. Jifeng W, Huapu L, Hu P. System dynamics model of urban transportation system and its application. System dynamics model of urban transportation system and its application. 2008; 8(3): p. 83-89.

14. United Nations. The buses of Brasil: Connectivity - Intelligent Transport Solution Brasil UNFCCC. [Online].; 2012 [cited 2020 January 30. Available from: https://unfccc.int/climate-action/momentum-for-change/lighthouse-activities/thebuses-of-brasil-connectivity-intelligent-transport-solution.

15. Ocalir-Akunal EV. Decision support systems in transport planning. Procedia 
engineering. 2016; 161: p. 1119-1126.

16. Engebrethsen E, Dauzère-Pérès $S$. Transportation mode selection in inventory models: A literature review. European Journal of Operational Research. 2018; 279(1): p. 1-25.

17. American Council for an Energy-Efficient Economy A. Transportation System Efficiency. [Online].; 2019 [cited 2020 January 20. Available from: https://www.aceee.org/topic/transportation-system-efficiency.

18. US Department of Energy. Transportation system efficiency. [Online].; 2019 [cited 2020 January 30. Available from: https://afdc.energy.gov/conserve/system_efficiency.html.

19. Georgantzas NC. Scenario-driven planning with system dynamics scenario-driven planning. System Dynamics: Theory and Applications. 2020;: p. 41-67.

20. Peherstorfer B, Willcox K. Dynamic data-driven model reduction: adapting reduced models from incomplete data. Advanced Modeling and Simulation in Engineering Sciences. 2016; 3(1): p. 1-22.

21. Sterman J. Business dynamics: systems thinking and modeling for a complex world Boston, Mass: Irwin/McGraw-Hill; 2000.

22. Suryani E, Chou S, Chen C. Dynamic simulation model of air cargo demand forecast and terminal capacity planning. Simulation Modelling Practice and Theory. 2012; 28: p. 27-41.

23. Brailsford SC, Eldabi T, Kunc M, Mustafee N, Osorio AF. Hybrid simulation modelling in operational research: A state-of-the-art review. European Journal of Operational Research. 2019; 278(3): p. 721-737.

24. Brailsford S, Hilton N. A comparison of discrete event simulation and system dynamics for modelling health care systems. Proceedings of the 26th meeting of the ORAHS Working Group 2000. 2001;: p. 18-39. 
25. Abbas K, Bell M. System dynamics applicability to transportation modeling. Transportation Research Part A: Policy and Practice. 1994; 28(5): p. 373-390.

26. Vensim Inc. How does Vensim compare to other system dynamics software? [Online].; 2015 [cited 2020 January 20. Available from: https://vensim.com/faqs/how-does-vensim-compare-to-other-system-dynamicssoftware/.

27. Albin S. Building a System Dynamics Model - Part 1: Conceptualization. [Online].; 1997 [cited 2020 January 20. Available from: https://ocw.mit.edu/courses/sloanschool-of-management/15-988-system-dynamics-self-study-fall-1998-spring1999/readings/building.pdf.

28. Government of Singapore. Commuters are more satisfied with public transport in 2018. [Online].; 2019 [cited 2020 January 30. Available from: https://www.ptc.gov.sg/newsroom/news-releases/newsroom-view/commuters-moresatisfied-with-public-transport-in-2018.

29. Hyde R, Smith D. Assessing the value of public transport as a network New Zealand: NZ Transport Agency; 2017.

30. Moses R, Mtoi E, Ruegg S, McBean H, Brinckerhoff P. Development of speed models for improving travel forecasting and highway performance evaluation Florida: Department of Transportation; 2013.

31. Li J, Chen X, Li X, Guo X. Evaluation of public transportation operation based on data envelopment analysis. Procedia-Social and Behavioral Sciences. 2013; 96: p. 148-155.

32. Dodson J, Mees P, Stone J, Burke M. The principles of public transport network planning: A review of the emerging literature with select examples. Urban Research Program. 2011; 15.

33. Markow M. Engineering economic analysis practices for highway investment (Vol. 424) NCHRP Synthesis: Transportation Research Board; 2012. 
34. Farber S, Marino M. Transit accessibility, land development and socioeconomic priority: A typology of planned station catchment areas in the Greater Toronto and Hamilton Area. Journal of Transport and Land Use. 2017; 1: p. 879-902.

35. Litman T. Land use impacts on transport. [Online].; 2005 [cited 2020 January 20. Available from: https://wisconsindot.gov/Documents/projects/data-plan/planres/landuse/victoria.pdf.

36. Cascetta E, Cartenì A, Montanino M. A new measure of accessibility based on perceived opportunities. Procedia-Social and Behavioral Sciences. 2013; 87: p. 117132.

37. Barlas Y. Formal aspects of model validity and validation in system dynamics. System Dynamics Review: The Journal of the System Dynamics Society. 1996; 12(3): p. 183-210.

38. Brose A, Fügenschuh A, Gausemeier P, Vierhaus I, Seliger G. System dynamic enhancement for the scenario technique. ZIB-Report. 2013; 13(24).

39. Suryani E, Chou S, Chen C. Air passenger demand forecasting and passenger terminal capacity expansion: A system dynamics framework. Expert Systems with Applications. 2010; 37(3): p. 2324-2339.

40. Suryani E. Dynamic simulation model of demand forecasting and capacity planning. Proceedings of the Annual Meeting of Science and Technology Studies (AMSTECS'11). 2011.

41. MacKechnie C. What is the passenger capacity of different modes of transit? [Online].; 2019 [cited 2020 January 20. Available from: https://www.thoughtco.com/passenger-capacity-of-transit-2798765.

42. Institute for Transportation \& Development Policy. What is BRT? [Online].; 2019 [cited 2020 January 25. Available from: https://www.itdp.org/library/standards-andguides/the-bus-rapid-transit-standard/what-is-brt/.

43. Kompasiana. The challenges of implementing brt in indonesia for the next 10 years 
(Tantangan penerapan BRT di Indonesia untuk 10 tahun ke depan). [Online].; 2015

[cited 2020 January 29. Available from: https://www.kompasiana.com/demographyurbanplanning/568314f570977369048b4568/tantangan-penerapan-brt-di-indonesiauntuk-10-tahun-ke-depan?page $=$ all. 